\title{
Comparative Incidence of Nephrotoxicity by Age Group among Adult Patients Receiving Vancomycin
}

Joseph J. Carreno $\cdot$ Anthony Jaworski $\cdot$

Rachel M. Kenney $\cdot$ Susan L. Davis

To view enhanced content go to www.infectiousdiseases-open.com

Received: June 26, 2013 / Published online: December 11, 2013

(C) The Author(s) 2013. This article is published with open access at Springerlink.com

\section{ABSTRACT}

Introduction: Little is known regarding agerelated risk of nephrotoxicity during vancomycin therapy after the publication of the 2009 vancomycin consensus guidelines for therapeutic drug monitoring. We sought to evaluate incidence and risk factors for acute kidney injury in three age groups.

Electronic supplementary material The online version of this article (doi:10.1007/s40121-013-0022-6) contains supplementary material, which is available to authorized users.

J. J. Carreno · A. Jaworski · R. M. Kenney ·

S. L. Davis $(\varangle)$

Henry Ford Hospital Department of Pharmacy

Services, Detroit, MI, USA

e-mail: sldavis@wayne.edu

J. J. Carreno · A. Jaworski · R. M. Kenney ·

S. L. Davis

Eugene Applebaum College of Pharmacy and Health Sciences, Wayne State University, 259 Mack. Ave., Detroit, MI 48201, USA

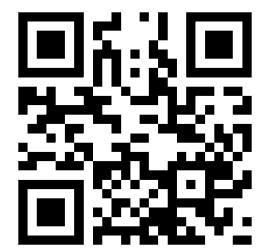

Enhanced content for this article is available on the journal web site: www.infectiousdiseases-open.com
Methods: Matched cohort study of patients receiving vancomycin, grouped by age: young adults (18-64 years), older adults (65-79 years) and very elderly ( $\geq 80$ years), matched on previously published risk factors for nephrotoxicity. Outcomes included traditional vancomycin nephrotoxicity and Acute Kidney Injury Network-modified definition of nephrotoxicity.

Results: The incidence of acute kidney injury was $34.1 \%$ vs. $34.1 \%$ vs. $31.8 \%$ in the young, older adults and very elderly groups, respectively $(p=0.97)$. In the logistic regression model, after adjusting for baseline risk factors, age was not a significant predictor of acute kidney injury. Lower respiratory tract infection (adjusted odds ratio [aOR] 5.18; 95\% confidence interval [CI] 2.15-12.41) and duration of treatment (aOR 1.12; 95\% CI 1.03-1.22) were found to be independently associated with outcome.

Conclusion: No differences in risk of acute kidney injury were identified between young, older, and very elderly adults when adjusting for other risk factors. Further research is required to identify strategies to optimize the safety of vancomycin in the aging population. 
Keywords: Acute kidney injury; Aged; Drug toxicity; Elderly; Infectious diseases; Nephrotoxicity; Vancomycin

\section{INTRODUCTION}

Vancomycin has long been the workhorse agent for management of infections due to methicillin-resistant Staphylococcus aureus (MRSA); however, its clinical use is limited by nephrotoxicity [1-10]. While older data suggested that nephrotoxicity was initially associated with impurities in original formulations [1, 11], newer data suggest that nephrotoxicity is associated with risk factors, including patient-specific risk factors [8, 9], concurrent nephrotoxins $[5-7,10]$ and greater vancomycin exposures [2, 3]. Risk factor identification has greatly improved the ability of clinicians to determine which patients are at high risk for nephrotoxicity.

Despite improvements in the literature and practice, there are still limited data on renal safety of vancomycin in the very elderly (age $\geq 80$ years old). In 2002, the United Nations deemed the very elderly to be the fastest growing age group worldwide [12]. As of 2010, in the United States, when a person survives up to age 80 , they are expected to live an additional 9.1 years [13]. This increased time at risk for infectious diseases, coupled with an increased prevalence of MRSA infections [14], establishes a great need for information on the safety of vancomycin in these patients.

Previous investigations have provided valuable insight into age-related differences in risk of nephrotoxicity with vancomycin use. Twenty years ago, Vance-Bryan et al. [7] conducted a retrospective cohort study examining the comparative incidence of nephrotoxicity in the elderly (age $\geq 60$ years) and young (age $<60$ years). This study observed an increase in nephrotoxicity in the elderly population; however, this difference was thought to be due to an unequal distribution of other risk factors, like use of loop diuretics [7]. Since then, routine targets for vancomycin serum trough concentrations have changed, with recommendations of troughs greater than $10 \mathrm{mg} / \mathrm{L}$ for all patients, and $15-20 \mathrm{mg} / \mathrm{L}$ for specific indications [15]. The most recent data observing vancomycin nephrotoxicity have linked elevated serum trough concentrations and nephrotoxicity $[3,5,9]$; some of the studies have adjusted for age, however, none have been designed a priori to compare nephrotoxicity across age groups. The present study was conducted to estimate the relative risk of nephrotoxicity in very elderly adults receiving vancomycin as compared to older (65-79 years) and younger adults ( $<65$ years) while controlling for differences in baseline risk of nephrotoxicity.

\section{MATERIALS AND METHODS}

\section{Study Design}

This was an institutional review boardapproved, retrospective, matched cohort study at an urban, tertiary care teaching hospital serving a wide variety of medical and surgical specialties. All procedures followed were in accordance with the ethical standards of the responsible committee on human experimentation (institutional and national) and with the Helsinki Declaration of 1975, as revised in 2000. Informed consent was waived by the institutional review board.

Patients receiving intravenous vancomycin between January 2011 and April 2013 were screened. Patients included were 
aged at least 18 years, received at least four consecutive vancomycin doses, and had at least one recorded vancomycin serum trough concentration during the course of therapy. Patients were excluded if they had concurrent acute kidney injury prior to initiation of vancomycin (defined as an increase in serum creatinine of $0.3 \mathrm{mg} / \mathrm{dL}$ or $50 \%$ within $48 \mathrm{~h}$ prior to starting vancomycin, or if urine output was $<0.5 \mathrm{~mL} / \mathrm{kg} / \mathrm{h}$ for at least $6 \mathrm{~h}$ immediately before the initiation of vancomycin), were pregnant, or had an absolute neutrophil count $<1,000$ cells $/ \mathrm{mm}^{3}$.

Patients were categorized by age as young (18-64 years), older adults (65-79 years) and very elderly ( $\geq 80$ years). Consecutive very elderly patients were matched 1:1:1 with consecutive young and older adult patients on the basis of four classes of risk factors for nephrotoxicity: (1) history of acute kidney injury [8] or pre-existing chronic renal disease (as noted by baseline serum creatinine $\geq 1.30 \mathrm{mg} / \mathrm{dL}$ ), (2) weight $\geq 110 \mathrm{~kg}$ or receipt of high-dose IV vancomycin (at least $4 \mathrm{~g}$ per day) [2], (3) concurrent receipt of nephrotoxins (e.g., acyclovir, IV aminoglycosides, IV amphotericin B, IV contrast dye, loop diuretics, IV colistin) [1, $6,16]$ with IV vancomycin, and (4) concurrent receipt of IV vasopressors (norepinephrine, phenylephrine, or dopamine) with IV vancomycin. Vancomycin was dosed as an intermittent infusion by clinical pharmacists in accordance with the 2009 consensus guidelines for vancomycin therapeutic drug monitoring [15]. The primary outcome of interest was nephrotoxicity, defined as an abrupt (within $48 \mathrm{~h}$ ) increase in serum creatinine of $0.5 \mathrm{mg} / \mathrm{dL}$ or $50 \%$ above baseline for at least two consecutive measurements [15]. Secondary outcomes included Acute Kidney Injury Network (AKIN)-modified definition of nephrotoxicity [8], defined as an increase in serum creatinine of $0.3 \mathrm{mg} / \mathrm{dL}$, a decrease in creatinine clearance of at least $50 \%$ or a decrease in urine output to $<0.5 \mathrm{~mL} / \mathrm{kg} / \mathrm{h}$ for at least $6 \mathrm{~h}$.

\section{Data Analysis}

Descriptive statistics were used to characterize the cohort with respect to patient demographics, treatment characteristics and outcomes. Categorical data were described as proportions, and continuous data were described as means and standard deviations or medians an interquartile ranges, as appropriate. Outcomes and patient characteristics were compared between age groups.

Odds ratios were calculated for odds of nephrotoxicity and acute kidney injury for each age group with the young group as a reference category. Categorical data were analyzed using Chi-square test. Continuous parametric data were analyzed using one-way analysis of variance. Continuous nonparametric data were analyzed via one-way Kruskal-Wallis analysis of variance test, where appropriate. Lastly, a multivariable logistic regression model was constructed to determine the association between the age group and nephrotoxicity and acute kidney injury. Age was entered into the model and any variables found to have an association with the outcome of interest $(p<0.20)$ or that had clinical rationale were considered for the multivariable logistic regression model using backwardstepwise regression. All analyses were conducted using SPSS $^{\circledR}$ software, version 21.0 (SSPS Inc., Chicago, IL, USA).

Sample size assumption was based on the risk of nephrotoxicity in previously published studies [2], with a 7-day median duration of therapy, maximum risk (approximately 35\%) in the very elderly and minimal risk (approximately 10\%) in the young group. In 
order to detect a difference at a 0.05 level of significance and with $80 \%$ power, approximately 40 patients were needed in each age group.

\section{RESULTS}

Data were obtained for 132 patients meeting inclusion criteria. There were 44 patients in each stratum. Baseline characteristics (Table 1) were similar between groups, with limited exceptions other than age-related differences. The most common indications for vancomycin treatment were lower respiratory tract, bloodstream and skin and soft tissue infections. All patients had vancomycin trough concentrations obtained at steady state: in the respective young, older adults and very elderly groups, $75.0 \%, 77.3 \%$ and $77.3 \%$ of patients had an initial concentration greater than $10 \mathrm{mg} / \mathrm{L}$, and $47.7 \%, 45.5 \%$ and $31.8 \%$ of patients had a $15 \mathrm{mg} / \mathrm{L}$ or greater concentration. The two most common baseline risk factors for nephrotoxicity were history of acute kidney injury or chronic kidney disease (36.4\%) and concurrent receipt of nephrotoxins (36.4\%). Duration of treatment was significantly longer in the elderly group vs. all other groups (9 vs. 7 days, respectively; $p=0.02)$.

There were seven episodes of nephrotoxicity and 44 episodes of acute kidney injury within the cohort. The incidence of nephrotoxicity was $2.3 \%, 9.1 \%$ and $4.5 \%$ in the young, older adult and very elderly groups, respectively $(p=0.35$, Fig. 1). The incidence of acute kidney injury was $34.1 \%, 34.1 \%$ and $31.8 \%$ in the young, older adults and very elderly groups, respectively $(p=0.97$, Fig. 1$)$. Relevant predictors for acute kidney injury, including all variables with $p<0.2$ in bivariate comparison, are listed in
Table 2. Since there were only seven episodes of nephrotoxicity, only acute kidney injury was explored in the multivariable analysis.

In the logistic regression model, age was entered into the model using the young group as the reference. Based on the pre-specified criteria for model entry and removal, age, lower respiratory tract infection, length of therapy and presence of at least two different risk factors at baseline were included in the final model. Age was not identified as a significant predictor. Adjusting for the presence of more than one baseline risk factor, both lower respiratory tract infection and longer duration of therapy were significant predictors for acute kidney injury.

\section{DISCUSSION}

In the era of the 2009 consensus vancomycin guidelines, no independent association between acute kidney injury and advanced age was found in this matched cohort. These findings are similar to work predating these consensus recommendations [7]. Therefore, clinicians should not routinely use age alone to assess the risk of nephrotoxicity in patients receiving vancomycin. Factors that were found to be associated with acute kidney injury in our study included lower respiratory tract infection and longer duration of therapy, which are also consistent with more recent observational studies [3, 9]. Importantly, the multivariable analysis of this study was based on the secondary endpoint of AKIN-defined nephrotoxicity. The AKIN method of identifying nephrotoxicity has been shown to be more sensitive than the traditional definition of nephrotoxicity [15], and also explains the higher incidence of acute kidney injury identified in this cohort. 
Table 1 Baseline characteristics

\begin{tabular}{|c|c|c|c|c|}
\hline Variable & $\begin{array}{l}\text { Young } \\
(n=44)\end{array}$ & $\begin{array}{l}\text { Older adults } \\
(n=44)\end{array}$ & $\begin{array}{l}\text { Very elderly } \\
(n=44)\end{array}$ & $p$ \\
\hline Age (years) & $52(41-59)$ & $70(66-75)$ & $87(82-90)$ & $<0.01$ \\
\hline Male sex & $21(48)$ & $19(43)$ & $20(46)$ & 0.91 \\
\hline Baseline SCr (mg/dL) & $0.86(0.67-1.2)$ & $1.00(0.71-1.24)$ & $1.07(0.96-1.36)$ & 0.01 \\
\hline $\mathrm{CrCl}(\mathrm{mL} / \mathrm{min})$ & $73(54-92)$ & $45(37-60)$ & $34(26-45)$ & $<0.01$ \\
\hline Charlson score & $1(0-3)$ & $2(1-3)$ & $2(1-3)$ & 0.11 \\
\hline \multicolumn{5}{|l|}{ Race } \\
\hline Caucasian & $18(40.9)$ & $11(25.0)$ & $19(43.2)$ & 0.11 \\
\hline African American & $21(47.7)$ & $21(47.7)$ & $22(50.0)$ & \\
\hline Hispanic & $1(2.3)$ & $0(0.0)$ & $0(0.0)$ & \\
\hline Asian & $1(2.3)$ & $4(9.1)$ & $0(0.0)$ & \\
\hline Other & $3(6.8)$ & $8(18.2)$ & $3(6.8)$ & \\
\hline \multicolumn{5}{|l|}{ Infection site ${ }^{\mathrm{a}}$} \\
\hline Abdominal & $1(2.3)$ & $3(6.8)$ & $0(0.0)$ & 0.16 \\
\hline Blood & $11(25.0)$ & $9(20.5)$ & $13(29.5)$ & 0.61 \\
\hline Bone & $3(6.8)$ & $1(2.3)$ & $1(2.3)$ & 0.44 \\
\hline Central nervous system & $3(6.8)$ & $0(0.0)$ & $4(9.1)$ & 0.14 \\
\hline Genitourinary & $2(4.5)$ & $7(15.9)$ & $8(18.2)$ & 0.12 \\
\hline Joint & $0(0)$ & $0(0)$ & $1(2.3)$ & 0.36 \\
\hline Lower respiratory tract & $13(29.5)$ & $19(43.2)$ & $17(38.6)$ & 0.40 \\
\hline Skin and soft tissue & $9(20.5)$ & $5(11.4)$ & $5(11.4)$ & 0.37 \\
\hline Wound & $2(4.5)$ & $0(0)$ & $0(0)$ & 0.13 \\
\hline Other & $3(6.8)$ & $2(4.5)$ & $1(2.3)$ & 0.59 \\
\hline Goal vancomycin trough $15-20 \mathrm{mg} / \mathrm{L}$ & $31(70.5)$ & $30(68.2)$ & $34(77.3)$ & 0.61 \\
\hline Length of treatment (days) & $7(5-9)$ & $9(6-12)$ & $7(5-10)$ & 0.05 \\
\hline \multicolumn{5}{|l|}{ Risk factors for nephrotoxicity } \\
\hline History of AKI or chronic kidney disease & $16(36.4)$ & $16(36.4)$ & $16(36.4)$ & 1.00 \\
\hline High-dose vancomycin $^{\mathrm{b}}$ or weight $\geq 110 \mathrm{~kg}$ & $1(2.3)$ & $1(2.3)$ & $1(2.3)$ & 1.00 \\
\hline Vasopressors & $2(4.5)$ & $2(4.5)$ & $2(4.5)$ & 1.00 \\
\hline Nephrotoxins ${ }^{c}$ & $16(36.4)$ & $16(36.4)$ & $1(36.4)$ & 1.00 \\
\hline
\end{tabular}

Data are median (interquartile range) or $n(\%)$

$A K I$ acute kidney injury, $\mathrm{CrCl}$ creatinine clearance, $S \mathrm{Cr}$ serum creatinine

${ }^{a}$ Infection sites are not mutually exclusive

b At least $4 \mathrm{~g}$ of vancomycin per day

c Acyclovir, IV aminoglycosides, IV amphotericin B, IV contrast dye, loop diuretics, IV colistin

There are several potential explanations for the finding that lower respiratory tract infection was associated with nephrotoxicity. Recent guidelines recommend that due to poor lung penetration of vancomycin [17], a target trough of $15-20 \mathrm{mg} / \mathrm{L}$ is utilized for these infections
$[15,18,19]$. This target trough has also been associated with increased incidence of nephrotoxicity $[3,5,6$, 9]. In the present study, targeting a trough concentration of $15-20 \mathrm{mg} / \mathrm{L}$ was associated with nephrotoxicity in bivariate analysis; because of 


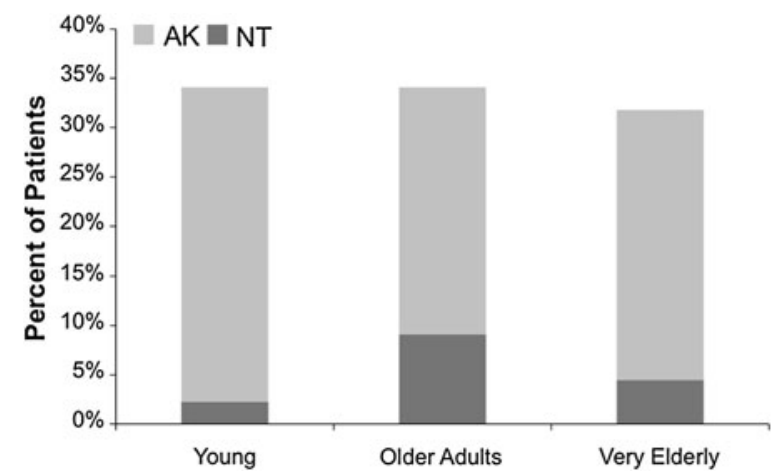

Fig. 1 Incidence of nephrotoxicity in each age group. $A K I$ acute kidney injury, NT nephrotoxicity

covariance with lower respiratory tract infections, the stronger bivariate predictor was used in the multivariate model. In addition, the associated pathology of sepsis in patients with lower respiratory tract infections may increase the risk of acute kidney injury. Sepsis has been shown in experimental models to increase the risk of acute kidney injury [20]; however, septic shock, as evidenced by use of vasopressors, was not common in this cohort.

This study is not without limitations. As with any retrospective study, causality cannot be proven, and data are subject to observer biases at the time of documentation. There is also the possibility that measured and unmeasured confounders influenced outcome. The matched cohort design with multivariable analysis may have reduced this effect. This is the first matched study to specifically examine the relationship between age and acute kidney injury during vancomycin therapy. These data must be considered carefully. Although a

Table 2 Bivariate and multivariate associations with acute kidney injury

\begin{tabular}{|c|c|c|c|c|c|c|}
\hline Variable & OR & $95 \% \mathrm{CI}$ & $p$ & aOR & $95 \% \mathrm{CI}$ & $p$ \\
\hline \multicolumn{7}{|l|}{ Age group } \\
\hline Young (reference) & 1.00 & $\mathrm{~N} / \mathrm{A}$ & $\mathrm{N} / \mathrm{A}$ & 1.00 & N/A & $\mathrm{N} / \mathrm{A}$ \\
\hline Older adults & 1.00 & $0.41-2.42$ & 1.00 & 0.69 & $0.25-1.92$ & 0.48 \\
\hline Very elderly & 0.90 & $0.37-2.20$ & 0.82 & 0.78 & $0.28-2.26$ & 0.80 \\
\hline $\mathrm{CrCl}(\mathrm{mL} / \mathrm{min})$ & 0.98 & $0.96-1.00$ & 0.05 & - & - & - \\
\hline Charlson score & 1.30 & $1.05-1.61$ & 0.02 & - & - & - \\
\hline \multicolumn{7}{|l|}{ Infection site ${ }^{\mathrm{a}}$} \\
\hline Blood & 0.36 & $0.14-0.94$ & 0.03 & - & - & - \\
\hline Genitourinary & 0.38 & $0.11-1.43$ & 0.14 & - & - & - \\
\hline Lower respiratory tract & 4.08 & $1.90-8.78$ & $<0.01$ & 5.18 & $2.15-12.41$ & $<0.01$ \\
\hline Goal vancomycin trough $15-20 \mathrm{mg} / \mathrm{L}$ & 2.21 & $0.91-5.36$ & 0.07 & - & - & - \\
\hline Length of treatment (days) & 1.08 & $1.00-1.16$ & 0.04 & 1.12 & $1.03-1.22$ & $<0.01$ \\
\hline \multicolumn{7}{|l|}{ Risk factors for nephrotoxicity } \\
\hline Vasopressors & 4.30 & $0.76-24.46$ & 0.10 & - & - & - \\
\hline Nephrotoxins & 2.06 & $0.98-4.35$ & 0.06 & - & - & - \\
\hline$\geq 2$ risk factors at baseline & 7.00 & $2.08-23.55$ & $<0.01$ & 6.94 & $1.81-26.66$ & $<0.01$ \\
\hline
\end{tabular}

$a O R$ adjusted odds ratio, $C I$ confidence interval, $\mathrm{CrCl}$ creatinine clearance, $O R$ odds ratio

${ }^{a}$ Infection sites are not mutually exclusive. Data are median (interquartile range) or $n$ (\%) 
matched cohort provides considerable evidence that age alone is not a significant risk factor for acute kidney injury during vancomycin therapy, extrapolation of kidney injury incidence within the general population is more difficult. These data provide an additional rationale for exercising caution when using vancomycin in patients requiring longer duration of therapy or with pre-existing risk factors, regardless of age.

\section{CONCLUSION}

In this matched cohort study, there was no difference detected in risk of nephrotoxicity or acute kidney injury between young, older, and very elderly adults receiving vancomycin in an acute care inpatient facility. Further research is required to identify strategies to optimize the safety of vancomycin in the aging population.

\section{ACKNOWLEDGMENTS}

The authors wish to thank Henry Ford Hospital Department of Pharmacy Services ID PRIME members for editorial review of the manuscript. No funding or sponsorship was received for this study or publication of this article.

These findings were presented in part as abstract at the 53rd ICAAC in Denver, CO, USA on September 11, 2013.

Dr. Susan L. Davis is the guarantor for this article, and takes responsibility for the integrity of the work as a whole.

Conflict of interest. Joseph J. Carreno, Anthony Jaworski and Rachel M. Kenney declare no conflict of interest.

Susan L. Davis has served as a paid consultant with Forest Inc., Durata, and Premier Inc.
Compliance with ethics guidelines. All procedures followed were in accordance with the ethical standards of the responsible committee on human experimentation (institutional and national) and with the Helsinki Declaration of 1975 , as revised in 2000. Informed consent was waived by the institutional review board.

Open Access. This article is distributed under the terms of the Creative Commons Attribution Noncommercial License which permits any noncommercial use, distribution, and reproduction in any medium, provided the original author(s) and the source are credited.

\section{REFERENCES}

1. Farber BF, Moellering RC Jr. Retrospective study of the toxicity of preparations of vancomycin from 1974 to 1981. Antimicrob Agents Chemother. 1983;23:138-41.

2. Lodise TP, Lomaestro B, Graves J, Drusano GL. Larger vancomycin doses (at least four grams per day) are associated with an increased incidence of nephrotoxicity. Antimicrob Agents Chemother. 2008;52:1330-6.

3. Lodise TP, Patel N, Lomaestro BM, Rodvold KA, Drusano GL. Relationship between initial vancomycin concentration-time profile and nephrotoxicity among hospitalized patients. Clin Infect Dis. 2009;49:507-14.

4. Patel N, Pai MP, Rodvold KA, Lomaestro B, Drusano GL, Lodise TP. Vancomycin: we can't get there from here. Clin Infect Dis. 2011;52:969-74.

5. Jeffres MN, Isakow W, Doherty JA, Micek ST, Kollef $\mathrm{MH}$. A retrospective analysis of possible renal toxicity associated with vancomycin in patients with health care-associated methicillin-resistant Staphylococcus aureus pneumonia. Clin Ther. 2007;29:1107-15.

6. Cano EL, Haque NZ, Welch VL, et al. Incidence of nephrotoxicity and association with vancomycin use in intensive care unit patients with pneumonia: retrospective analysis of the IMPACT-HAP Database. Clin Ther. 2012;34:149-57. 
7. Vance-Bryan K, Rotschafer JC, Gilliland SS, Rodvold KA, Fitzgerald CM, Guay DR. A comparative assessment of vancomycin-associated nephrotoxicity in the young versus the elderly hospitalized patient. J Antimicrob Chemother. 1994;33:811-21.

8. Minejima E, Choi J, Beringer P, Lou M, Tse E, WongBeringer A. Applying new diagnostic criteria for acute kidney injury to facilitate early identification of nephrotoxicity in vancomycin-treated patients. Antimicrob Agents Chemother. 2011;55:3278-83.

9. Bosso JA, Nappi J, Rudisill C, et al. Relationship between vancomycin trough concentrations and nephrotoxicity: a prospective multicenter trial. Antimicrob Agents Chemother. 2011;55:5475-9.

10. Rybak MJ, Albrecht LM, Boike SC, Chandrasekar $\mathrm{PH}$. Nephrotoxicity of vancomycin, alone and with an aminoglycoside. J Antimicrob Chemother. 1990;25:679-87.

11. Levine DP. Vancomycin: a history. Clin Infect Dis. 2006;42(Suppl 1):S5-12.

12. United Nations. World Population Ageing: 1950-2050 Executive Summary [Webpage]. Internet: United Nations; 2002. Available from: http://www.un.org/esa/population/publications/ worldageing19502050/pdf/62executivesummary_ english.pdf. Accessed 10 June 2013.

13. Murphy SL, Xu J, Kochanek KD. Deaths: final data for 2010. Natl Vital Statist Rep. 2013;61:1-55.

14. Klein E, Smith DL, Laxminarayan R. Hospitalizations and deaths caused by methicillin- resistant Staphylococcus aureus, United States, 1999-2005. Emerg Infect Dis. 2007;13:1840-6.

15. Rybak MJ, Lomaestro BM, Rotschafer JC, et al. Vancomycin therapeutic guidelines: a summary of consensus recommendations from the infectious diseases Society of America, the American Society of Health-System Pharmacists, and the Society of Infectious Diseases Pharmacists. Clin Infect Dis. 2009;49:325-7.

16. Pauly DJ, Musa DM, Lestico MR, Lindstrom MJ, Hetsko CM. Risk of nephrotoxicity with combination vancomycin-aminoglycoside antibiotic therapy. Pharmacotherapy. 1990;10:378-82.

17. Lodise TP, Drusano GL, Butterfield JM, Scoville J, Gotfried M, Rodvold KA. Penetration of vancomycin into epithelial lining fluid in healthy volunteers. Antimicrob Agents Chemother. 2011;55:5507-11.

18. American Thoracic Society. Infectious Diseases Society of America. Guidelines for the management of adults with hospital-acquired, ventilator-associated, and healthcare-associated pneumonia. Am J Respir Crit Care Med. $2005 ; 171: 388-416$.

19. Liu C, Bayer A, Cosgrove SE, et al. Clinical practice guidelines by the infectious diseases Society of America for the treatment of methicillin-resistant Staphylococcus aureus infections in adults and children. Clin Infect Dis. 2011;52:e18-55.

20. Zarjou A, Agarwal A. Sepsis and acute kidney injury. J Am Soc Nephrol. 2011;22:999-1006. 